\title{
HOW TO PRODUCE VIDEO LECTURES TO ENGAGE STUDENTS AND DELIVER THE MAXIMUM AMOUNT OF INFORMATION
}

\author{
Linda Alksne \\ Liepaja University, Latvia
}

\begin{abstract}
This paper is dedicated to the analysis of literature about video lectures and finding out the conditions and rules for planning and delivering a good video lecture for modern learning. Different publications and materials on the design and delivery experience of video lectures in learning situations have been analysed. The presented set of the design and delivery experience data of video lectures could be used to create more efficient methods of improving the instruction quality of video lectures.
\end{abstract}

Keywords: entropy, experience, video lecture, video production.

\section{Introduction}

The author thinks that it is important to start with analysing different researches on video lectures and to give a set of experience in this field to find out how to achieve the main rule. And the main rule for a good video lecture is that it should be easily perceptible to the students. Authors' main thought for this paper is capture a video lecture based on previously collected rules and conditions for video lectures and to calculate the entropy of this video lecture and to compare it with the results of the video lecture which has been captured without observing any rules.

The author has discussed the importance of entropy in language in the publication "Latvian language as a code in different communication channels". In that article, the Latvian language has been studied as a code of literary communication channels such as the press, poetry, prose and legal literature. The entropy of the Latvian language has been calculated and compared with that of other languages (Bajarune, 2015). The analysis of a video lecture as a code is a sequel to the researches that have been made before.

Natural language is one of the main ways of communication. As the system of signs, it is a tool to send and receive information. With its system of signs, symbols and rules of their combinations, connections and typesetting, language is a unique communication code according to which all other non-verbal codes are being used (Shannon, 1948). 
From the point of view of the communication theory, any language is a code. How informative this code is, has been characterized by its Shannon entropy. If the diversity of language is greater, Shannon entropy is also higher (University of Texas at Austin, 2015).

Although many educational organizations create and share video lectures, no conventional standard for creating a video lecture is available. No guidelines for the presentation style of video lectures are available either (Illioudi, 2013).

Importantly, the merits and limitations of each video lecture type for online learning have not yet been thoroughly investigated. In sum, despite a growing number and variety of online educational video lectures, their effectiveness in terms of learning and usability is hardly understood (Chorianopoulos, 2013).

This purpose of this paper is to offer a set of experience which might help teachers, instructors and video producers take better advantage of the online video format.

\section{Methods and materials}

Most researchers like Benett, Brecht and Chen analyze the benefits of video lectures or compares different types of video lectures.

The advantages of multimedia learning are many and they are shared by all authors.

Compared with the traditional teaching methods, the multimedia teaching methods have many advantages.

The traditional teaching model has lasted for many years without any changes. The emergence of multimedia has urged the instructors to research and develop new teaching devices in order to improve the teaching methods and the quality of teaching so in order to free teachers from the traditional blackboard. Teachers no longer have to stand in front of the audience monotonously delivering a lecture while the students impassively take down notes. The new teaching method improves the teaching process and inspires students to become enthusiastic learners.

The multimedia teaching method creates a rich and relaxed learning environment for students. It promotes content echoism, diversifies expression, and stimulates the sensory reaction of students, in many ways embodying the situational teaching method and thus creating a pleasant, vivid study atmosphere. In this way, students' fatigue and tension after class can be eliminated to some extent, so that the students' intellectual and non-intellectual faculties interact promoting their development and they can learn independently and actively, obtaining better results in their studies.

The teaching time has been increased by multimedia teaching of the teachers in the class, improves the quality of the content and enhances the 
understanding and knowledge of the content by students. At the same time, it is also a challenge for teachers because it takes much more time and efforts for them to plan the lessons and prepare the courseware than the traditional teaching method but it improves the quality of teaching.

Using different multimedia materials and activities enlarges the scope and area of teaching. The traditional teaching model focuses on face-to-face live lecture or small class lecture, and in case of an intensive class, the effectiveness of teaching cannot be guaranteed, while multimedia teaching can be used for large areas, large scale and remote teaching. It can relieve the burden of heavily crowded classes and courses for teachers and hence improve the teaching efficiency.

Multimedia teaching is conducive to the implementation of bi-directional teaching and improving the teaching efficiency. In traditional teaching, it is difficult for teachers to communicate with every student, while multimedia teaching can take full advantage of the interactional function of the computer to put bi-directional teaching into practice. With the timely and high quality feedback of the computer through the communication between the student and the computer, the learning situation of each student can be controlled. As for the knowledge, multimedia teaching can turn abstract knowledge into concrete knowledge, complex things into simple things and difficult material into easy material. Computers reveal the essence of inexplicable problems and enhance the teaching efficiency.

There are also several disadvantages in multimedia teaching. Some teachers think that to promote the modernization of education and reform the teaching model, computer-assisted instruction is an obligatory tool. Thus, regardless of the actual need, teachers use the computer from the beginning of the class to the end. They have substituted the traditional teaching model of cramming educational material by cramming electronic material. Educational psychologists consider that the overused computer-aided instruction in the class may have an adverse effect, it may distract the students' attention, The more unintended attention is demanded from the students the greater disruption in the process of teaching and information transmission occurs, Information received in such a way has no use for the students.

Teachers play a leading role in teaching activities, but students have the main role in cognitive activities. The teaching process depends on the teaching environment for mutual interaction and influence between teachers and students in developing cognitive activities. Although, multimedia can provide a wealth of multimedia information being superior to the traditional teaching method of information transmission, it cannot achieve emotional teaching objectives or replace traditional teaching in this respect. Multimedia teaching often makes the class atmosphere dull. Students lack emotional interaction. They are not 
stimulated to learn autonomously and teaching effectiveness cannot be guaranteed.

The implementation of multimedia devices can make the imparting of knowledge clearer and more comprehensive. However, the use of multimedia can also lead the teachers to think that it is not necessary to add their own explanations, examples and conclusions to the comprehensive, systematic and detailed information of the multimedia. In fact, a definition, theorem, the calculation process of the problem, the calculation method and technique cannot be explicitly, vividly explained by the multimedia courseware alone. Generally speaking, the basic content of the lesson presented without any commentaries cannot substitute the teacher for specific content illustration. Without the teacher's explanations, students just have a general impression of the content without any deep understanding of the difficult points.

To cater for the interest of the students, many coursewares pursue superficial innovations: excessively strong colors, pictures and animations. Students are excited by the vivid audio-visual courseware but the actual results may not be satisfying. Through the diversity of the interface, the students' perception can be stimulated and deepened psychologically, regardless of their ability to distinguish the primary from the secondary, and some screens even become a drag for teaching. In these slick coursewares, a joyful atmosphere is taken for the ultimate goal of learning but it decreases the effectiveness of teaching in the end (Dai, 2012).

Videoing face-to-face lectures are growing in popularity in higher education. When used appropriately, a video can be a powerful teaching medium as exemplified by many researchers. Video lectures can attract a student's attention and motivate him or her to learn, also when it is necessary to expose students to things they would not otherwise have the opportunity to see (e.g. medical procedures), or when it is necessary to 'humanize' a topic (e.g., showing dramatizations or films when teaching about the war) (Bennet, 2007).

Features of interactive study, student control, and active learning are present in the use of video lectures, because learning is active when students seek explanations. The course instructor controls the available content, but the students may choose the segments of the video lectures they want to study (Brecht, 2012).

Wiese and Newton (2013) have summarized the advantages of lecture capture for students as increased satisfaction, enhanced understanding of the content, clarification of difficult topics, improved accuracy of course notes, and increased accessibility for non-native English speaking students. For instructors who use this method, the number of requests for clarification have decreased (Wiese, 2013). 
Chen and Wang (2011) have investigated how multimedia materials presented in different styles affect the learners' emotions and their performance. Their results suggest that video-based multimedia materials containing moving images with audio, and animated interaction-based multimedia materials, which integrate the text and animated images with interactive features generate the best learning performance and the most positive emotions among static text- and image-based multimedia materials. (Chen, 2011).

There are different styles of video lectures. The lecture capture type simply records an instructor's presentation for online viewing. The video typically contains PowerPoint slides, the instructor's voice, and occasionally a video recording of the instructor with text on a whiteboard.

The voice-over type synchronizes audio recordings of a lecture and accompanying PowerPoint slides via specialized lecture recording software (e.g., Microsoft Producer or PowerCam).

The picture-in-picture type displays an instructor's image and lecture slides and contains the instructor's voice, subtitles, or even flash animation. Thus, this type distinguishes between an instructor's video feed and slides, as well as requires elaborate post-production.

Khan-style video lectures rely mainly on handwritten tutorials produced by using a digital pen and tablet, with the teacher's audio voice-over.

It has been proven that the voice-over presentation type generates the highest sustained attention (Chen, 2015).

Not only the style but also the design of video lectures affects the students' understanding.

Brecht gives us information from his research from a university in USA. Three different video designs have been tested. $1^{\text {st }}$ design differed significantly from $2^{\text {nd }}$ and $3^{\text {rd }}$ designs. $1^{\text {st }}$ design was developed and tested first. Following the analysis of its survey results and consideration of anecdotal comments from students for design improvement, $2^{\text {nd }}$ design was developed. $2^{\text {nd }}$ design was tested in the following course-term. Then, following the analysis of $2^{\text {nd }}$ design survey results, $3^{\text {rd }}$ design was developed and tested.

Videos with a strong presentation of relief and change-of-pace elements $\left(2^{\text {nd }}\right.$ design use of graphics and sounds) are the most effective models for learning. This suggests that student attentiveness and engagement is a subtle issue in studying (Brecht, 2012).

Some researchers have measured the engagement with which students are watching each video. The engagement time is a standard metric used by both free video providers such as YouTube and enterprise providers such as Wistia.

The data prove that shorter videos are more engaging than longer videos. For videos 2 minutes and under, you should strive to make your content as short as possible to guarantee the highest engagement. If your video is 30 seconds or 
under, it is very likely that most people will watch it all the way through (Wistia, 2013).

Full classroom lecture content in video lectures has a typical length of 1-1 1/4 hours.

Whatley and Ahmad (2007) implicitly recognize limitations on the time the students will commit to reviewing classroom lectures for exams (Whatley, 2007). They have developed 5-10 minute summary videos which outline the main points from weekly class-room lectures. Students use PowerPoint slides for more-detailed information (Brecht, 2012).

Students usually are engaged more by talking-head videos. They seem to think that a human face provides a more "intimate and personal" feeling and breaks up the monotony of PowerPoint slides and code screencasts. It is recommended to record the instructor's face and then insert it into the presentation video at opportune times.

The faces of talking instructors are usually filmed in a tight frame, often making direct eye contact with the students, while the instructor who is standing behind a podium, often looks around the room and not directly at the camera. Video producers call this desirable trait "personalization" - the students feel that the video is being directed right at them, rather than at an unnamed crowd.

It is recommended to try filming in an informal setting where the instructor can make good eye contact, since it costs less and might be more effective than a professional studio.

Tutorials, which involve step-by-step problem solving across all Khan-style tutorial videos (i.e., an instructor drawing on a digital tablet) are more engaging than PowerPoint slides and/or code screencasts. Khan-style tutorials require more pre-production planning than presenting slides or typing a code into a text editor. The most effective Khan-style tutorials are those made by instructors with a clear handwriting, good drawing skills, and careful layout planning so as not to overcrowd the canvas. It has been recommended to record Khan-style tutorials when possible. If slides or a code must be displayed, emphasis should be added by sketching over the slides and the code using a digital tablet.

The pre-production (i.e., planning) phase has the largest impact on the students' engagement in the resulting videos. Even recording traditional onehour lectures in front of a live classroom if the instructors have carefully planned each hour is not so effective than a series of short, discrete chunks that could easily be edited later for online distribution. It is useful to invest in a preproduction effort, even if the instructors insist on recording live classroom lectures.

Students generally engage more in videos where instructors speak faster. Some practitioners recommend 160 words per minute as the optimum speaking rate for presentations (Williams, 1998). It is recommended to work with 
instructors to bring out their natural enthusiasm, reassure them that speaking fast is effective.

Students engage differently in lectures and tutorials. Lecture videos usually present conceptual (declarative) knowledge, whereas tutorials present procedural knowledge. Figure 1 shows that students only watch on average, 2 to 3 minutes of each tutorial video, regardless of its length. Figure 2 shows that students rewatch tutorials more frequently than lectures.

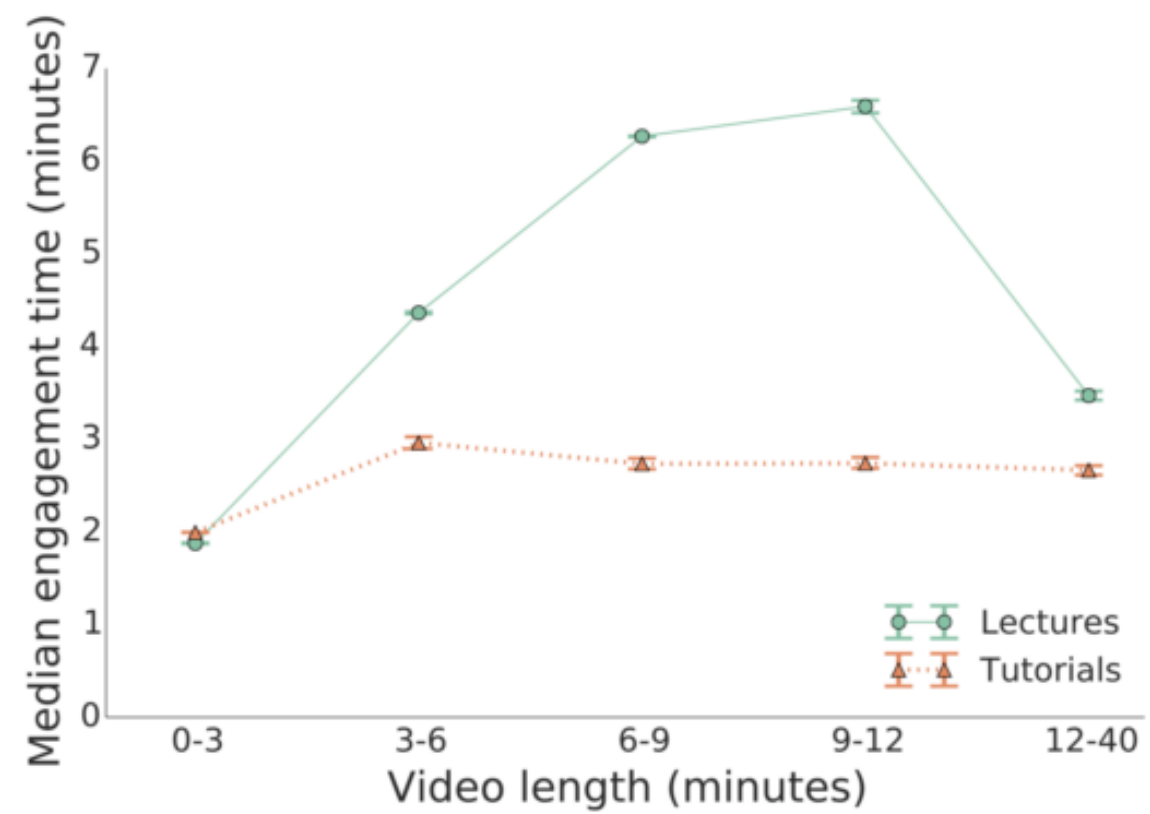

Fig. 1 Median engagement times versus video length for lecture and tutorial videos

(Guo, 2014)

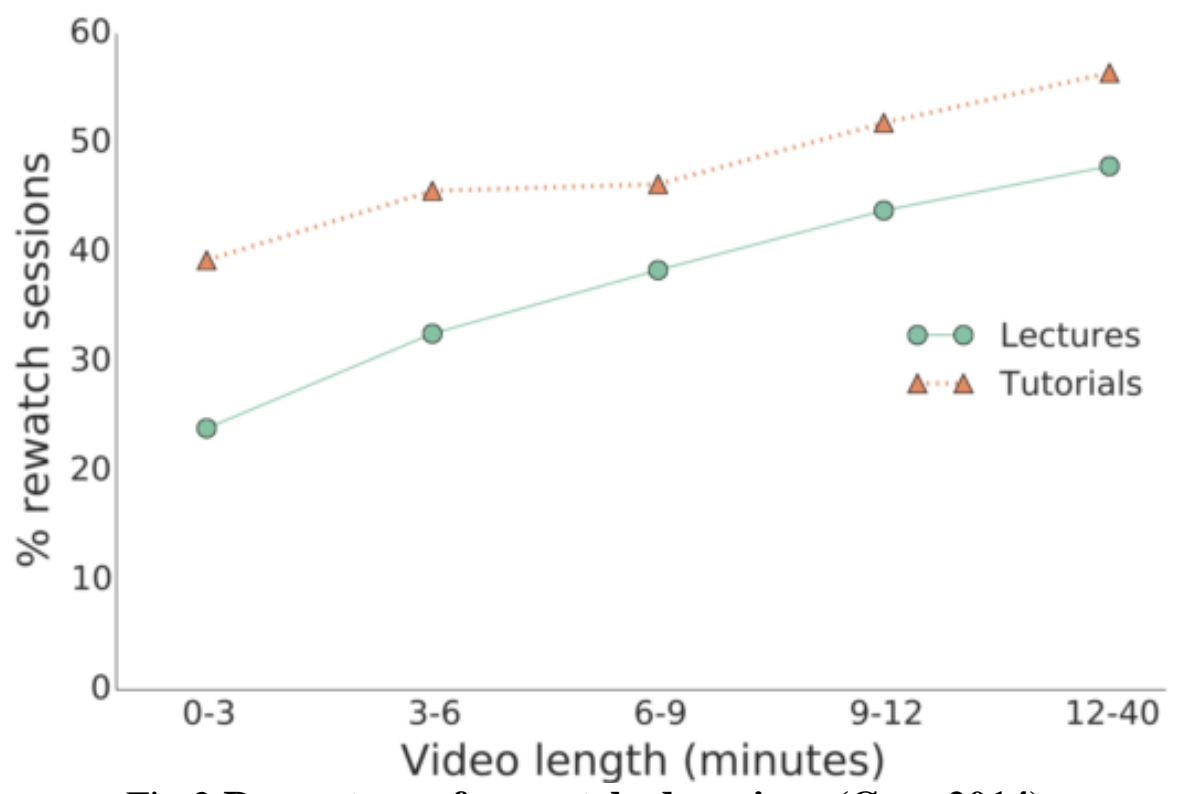

Fig.2 Percentage of re-watched sessions $($ Guo, 2014) 
These findings suggest that students will often re-watch and jump to relevant parts of longer tutorial videos. Adding hyperlink bookmarks or visual signposts on tutorial videos, such as big blocks of text to signify transitions, might facilitate skimming and re-watching. In contrast, students expect a lecture to be a continuous stream of information, so instructors should provide a good first-time watching experience. Instructors should adopt different production strategies for lectures and tutorials, since students use them in different ways. It is recommended for lecture videos to optimize the first- time watching experience. For tutorials, the length does not matter as much as support rewatching and skimming (Guo, 2014).

Video Production Guidelines have been issued by the ARSC Online Media Committee (OMC) and approved by the ARSC Board of Directors on 27 May 2015. The following guidelines are not requirements. They are intended to be used as guidance for capturing and producing the best quality video and audio materials having a number of variable factors, e.g., equipment limitations.

Setup and Capture:

- Lighting and visibility: Capture videos in well-lit areas; the subject of the videos should be easily discernable.

- Framing and focus: All shots should be clearly focused and wellframed; zooming should be used only for focusing attention and should otherwise generally be avoided.

- Stability: Use a tripod or another stabilizing device, if available. Keep the camera as still as possible.

- Audio: The sound should be audible and clearly understood throughout the video, with minimal to no ambient noise. The use of an external microphone is recommended for minimal interference and maximum clarity.

Editing

- Inlay text: Adding the text to the video, choose a standard font. Proofread the text for accuracy and grammar.

- Effects: Fade ins/fade outs, etc., should not detract from the message of the video. They should be smooth and not abrupt and choppy.

- Dead air: Edit out when possible.

- Background noise: Background noise, breaks, skips, hissing should be edited out.

- Volume control: Equalize the volume so that one speaker or subject is not noticeably louder than the other.

- Background music/audio: If adding background audio intentionally, balance with primary audio as best as possible. 
- Extended intros, bios, etc.: Extensive introductory material should be edited out and included in the written YouTube description. Cut excess text and submit it in a separate text document along with the video. The YouTube manager will add it to the description field.

Technical Standards. The following technical standards should be followed as much as possible.

- $\quad$ Preferred file formats: MP4 with H.264 codec.

- Aspect ratio: Native aspect ratio without letterboxing (e.g., 16:9). If a mobile device is used, shoot in landscape.

- Resolution: High definition video at either 1280x720, 1920x1080, or higher.

- $\quad$ Preferred audio format: AAC.

- Original video source: Avoid re-encoding prior to uploading as much as possible (Association for recorded sound collections, 2016).

Naturally, a video production should not distract the face-to-face teaching session. Thus, the production must be as transparent as possible when a video is produced from a face-to-face teaching situation. Transparency here means that the lecturer can concentrate on lecturing without having to significantly adapt the teaching and that the technology involved would not disturb and divert attention from the teaching. It is also hoped that the technology and recording would not distract the students from participating in face-to-face teaching.

The aim in making lecture videos available is to provide students who study with the help of videos with starting points that are equal to those of faceto-face students. For this reason, the general approach must be such that all the material shown in the classroom is also shown in the video, be it lecture material or text written by the lecturer.

One of the aims of video use is, typically, to add flexibility to study. For this to occur, the video production must cover all the teaching provided as comprehensively as possible. The recording system used, and above all the practices constructed around it, must be able to manage with also larger volumes of video production while satisfying all other requirements set for it. Flexibility is also increased if the videos are made viewable on as many technological platforms as possible.

When planning a video production, it is important to pay attention to the format the videos are produced in and whether to enable their viewing for example with mobile equipment. Changing the video format afterwards can be a fairly laborious and expensive process (Myllymaki, 2014).

It is necessary first of all to inform the research objectives to all persons whose images will be recorded and ask each of them to sign a permission to use their images. 
In case video recordings have been made, it is necessary to produce a short edition of the material in which the study participants could see themselves and have a general idea of the results (Garcez, 2011).

Instructors should anticipate that course materials previously used in faceto-face classes (and even in other blended or online situations) may need to be re-designed for delivery in a video lecture (University of British Columbia, 2014).

There are different methods to improve multimedia teaching.

First, it is important to select the teaching methods according to the teaching content and target. When making plans for teaching, teachers should start from the specific teaching content and targets. The implementation of multimedia should be arranged scientifically according to derivation writing, class discussion and experimental operation and other means alternatively. Teachers should pay attention to the coherence and integration of different teaching methods, make good use of this modern multimedia teaching device.

Second - to make excellent multimedia courseware.

The diversity of production methods, using software tools of multimedia courseware makes the content layout organization vary. Firstly, in the textual representation of the courseware content, the amount of the content and the expression methods should be taken into consideration. Too many words will seriously affect the quality of the courseware and the interests of the students. The e-learning materials without deleting any content of the source text will not yield a good teaching effect. When making courseware, the focal points, difficult points and key points should be highlighted in special color and script to show the difference, to strengthen the impact of visual effects, to enhance the impression in the students' minds, thereby improving the teaching quality. Secondly, graphic color in multimedia electronic courseware layout should have distinctive individual features of the respective teachers and correspond to the character of the course, but the layout colors should not be too diversified and the color and the brightness contrast should not be too intense.

Instructors should plan the teaching schedule accurately. Even an elaborate, comprehensive and excellent courseware will make the understanding of the content difficult, if the playing speed or teaching rhythm and elaboration have not been appropriately arranged.

Instructors should use a combination of multimedia teaching and traditional teaching. Traditional teaching media include a teaching board, wall charts, models, tape recorders, slide projectors, VCR and projectors and so on which have their advantages. Traditional teaching media are simple and convenient for operation. They have some special features, such as still-life displays, entity zooming and three-dimension displaying by using the slide projector, the computer does not have these functions. By using traditional teaching methods, 
communication between the students can be easily strengthened and the students' initiative can also be improved. Therefore, teachers must combine the multimedia teaching method with the traditional teaching method to achieve better teaching results.

Of course, it is necessary to invest in multimedia teaching. Professional courseware developers can form a small independent courseware by combining various contents and compile a product library, so the teachers can pick out the courseware they need and according to the actual situation form the sharing courseware library, thus enhancing the efficiency and quality of teaching. Schools have to send specially assigned persons to regularly check and update the multimedia classrooms, equipment and courseware libraries to ensure the maintenance and management of multimedia teaching (Dai, 2012).

\section{Results and discussion}

Summarizing investigation, the author offers set of rules on how to produce a good video lecture.

- Producers should try to follow the technical guidelines for the setup, capture, editing and setting of technical standards;

- The technology involved should not disturb or divert the students' attention from teaching;

- The recording system used must be able to manage also larger volumes of video production;

- The videos should be made viewable on as many platforms as possible;

- Attention should be payed to the format the videos are produced in;

- The voice-over presentation type video lecture attracts the highest sustained attention;

- Video producers should try filming in an informal setting where the instructor can make good eye contact;

- Videos with a strong presentation of relief and change-of-pace elements are most effective for learning;

- The layout colors should not be too diversified;

- Shorter videos are more engaging than longer ones;

- In making tutorials, Khan-style tutorial videos are more engaging than PowerPoint slides and/or code screencasts;

- When filming a video text should be written in clear handwriting and good drawing skills should be used;

- 160 words per minute are recommended as the optimum speaking rate for presentations; 
- Instructors should make a pre-production effort. The planning phase has the largest impact on the engagement of the resulting videos;

- Full classroom lecture content should be conveyed in 5-10 minute summary videos;

- The first-time watching experience for video lectures should be optimized;

- All material shown in the classroom can also be shown in a video;

- The textual representation of the courseware content should not be too long.

\section{Conslusions}

One of the most rated benefits face-to-face lecture recordings is that it enables students who are often absent from the regular lectures to improve their course grade by viewing the lectures online. So author agrees with Wieling, 2010, and also values it as student herself.

From experience of author and other universities to start capturing video lectures only a few of the software features are needed. So it is not very difficult to start videoing lectures or multimedia materials. Usually there are IT departments at universities which do all the searching of better technologies, testing, led trainings and support all the technical field. But usually instructors or teachers are afraid to start video lectures because they lack experience. That is why the author thinks it is very useful to have some guidelines not only for how to make videos, but also how to create videos saturated with information and easy to perceive.

Dominzo, 2008 says that a good lecture can be both motivating and exciting and gives lecturers the chance to be an inspirational role model for their students. Whatever the subject of a lecture, when it is delivered compellingly and there is a high level of engagement between the audience and the lecturer, it will not be forgotten easily. Author of this paper thinks that these guidelines give tips on how to achieve all these qualities also through video lectures.

Guo, 2014 have noticed that whenever a new communication medium arrives, people first tend to use it just like they used the existing media. As time progresses, people eventually develop creative ways to take full advantage of the new medium. The findings from all these papers can help to inform instructors and video producers about how to make the most of online videos for education. Academics may have to think more creatively about how to integrate engaging digital recordings into study programs.

The conclusions of this paper will be used for analyzing a video lecture as a code, where the entropy of the video lecture produced after these guidelines and 
recommendations will be calculated. It will give more information about multimedia materials and the advantages they give to students.

Also these tips will be useful for Riga Technical University IT help desk which provides support to lecture recording and tries to encourage professors to be active and to record lectures.

A TV studio is being planned also at Riga Technical University and instructors could use these recommendations for recording video materials. The author works at this IT help desk as a manager. That is why this paper is very useful both for studies and practice.

These recommendations will be also used to capture a good video lecture and to calculate entropy.

The presented set of video lecture design and delivery experience data could be used to create more efficient methods for improving the learning quality of video lectures.

\section{References}

Association for recorded sound collections. Available from Internet http://www.arscaudio.org/committees/video_production_guidelines.html

Bajarune, L., \& Ozols, A. (2015). Latvian language as a code in different communication channels, 3, 11-16.

Bennett, E, Maniar, N. (2007). Are videoed lectures an effective teaching tool?, 1-7.

Brecht, H. D. (2012). Learning from Online Video Lectures. Journal of Information Technology Education, 11.

Brecht, H. D., \& Ogilby, S. M. (2008). Enabling a Comprehensive Teaching Strategy: Video Lectures. Journal of Information Technology Education, 7, 71-86. Retrieved from http://go.galegroup.com/ps/i.do?action=interpret\&id=GALE|A199685531\&v=2.1\&u=g gcl\&it=r\&p=AONE\&sw=w\&authCount $=1$

Chen, C.-M., \& Wu, C.-H. (2015). Effects of different video lecture types on sustained attention, emotion, cognitive load, and learning performance. Computers \& Education, 80, 108-121. http://doi.org/10.1016/j.compedu.2014.08.015

Chorianopoulos, K., \& Giannakos, M. N. Usability design for video lectures. In The 11th European Conference on interactive TV and video, June 24e26, Como, Italy, 2013. 163164.

Dai, W., \& Fan, L. (2012). Discussion about the Pros and Cons and Recommendations for Multimedia Teaching in Local Vocational Schools. Physics Procedia, 33, 1144-1148. http://doi.org/10.1016/j.phpro.2012.05.188

Domizio, P. (2008). Giving a good lecture. Diagnostic Histopathology, 14(6), 284-288. http://doi.org/10.1016/j.mpdhp.2008.04.004

Effects of different video lecture types on sustained attention, emotion, cognitive load, and learning performance. Computers \& Education, 80, 108-121. Available from Internet http://doi.org/10.1016/j.compedu.2014.08.015

Garcez, A., \& Eisenberg, Z. (n.d.). Production and analysis of video recordings in qualitative research. Qualitative Research, 249-260. 
Linda Alksne. How to Produce Video Lectures to Engage Students and Deliver the Maximum Amount of Information

Google. YouTube Analytics. Available from Internet http://www.youtube.com/ yt/playbook/yt-analytics.html\#details.

Guo, P., Kim, J., \& Rubin, R. (2014). How video production affects student engagement: An empirical study of mooc videos. Proceedings of the First ACM Conference on Learning at Scale Conference, 41-50. http://doi.org/10.1145/2556325.2566239

Ilioudi, C., Giannakos, M. N., \& Chorianopoulos, K. (2013). Investigating differences among the commonly used video lecture styles. In CEUR Workshop Proceedings (Vol. 983, pp. 21-26). CEUR-WS. Retrieved from http://www.scopus.com/inward/record.url?eid=2s2.0-84922519277\&partnerID=tZOtx3y1

Phillips, J. A. (2015). Replacing traditional live lectures with online learning modules: Effects on learning and student perceptions. Currents in Pharmacy Teaching and Learning, 7(6), 738-744. http://doi.org/10.1016/j.cptl.2015.08.009

Shannon, C.E., A Mathematical Theory of Communication. The Bell System Technical Journal,Vol. 27, 1948. pp. 379-423, 623-656.

Shelton, E.N., Faculty support and student retention. Journal of Nursing Education 42 (2), 68e76, 2013.

University of Texas at Austin "Compuer science Home page" [Onine] Available from Internet https://www.cs.utexas.edu/ eberlein/cs337/errorDetection3.pdf [Acessed Jan 20, 2015]

Wieling, M. B., \& Hofman, W. H. A. (2010). The impact of online video lecture recordings and automated feedback on student performance. Computers \& Education, 54(4), 992998. http://doi.org/10.1016/j.compedu.2009.10.002

Wiese, C., \& Newton, G. (2013). Use of lecture capture in undergraduate biological science education. The Canadian Journal for the Scholarship of Teaching and Learning, 4(2).

Wistia. Does length matter? It does for video! , Sept. 2013. Available from Internet $\mathrm{http}: / /$ wistia.com/blog/does-length-matter-it-does-for-video

Williams, J. R. Guidelines for the use of multimedia in instruction. Proceedings of the Human Factors and Ergonomics Society Annual Meeting 42, 20, 1998. 1447-1451. 